DOI: http://dx.doi.org/10.30684/etj.37.4C.5

The First International Conference of Engineering Education (1 ${ }^{\text {st }}$ ICEE 2019), Iraq, Baghdad,

9-10 January 2019

\section{Ameen Al-juboori}

Al-Mustaqbal University College Hilla, Iraq, ameenaljuboori@mustaqbal-college.edu.iq

\section{Aws A. Al-Akam}

Al-Mustaqbal University College Hilla, Iraq.a.a.alakam@mustaqbalcollege.edu.iq

\section{Amir N. Saud}

Al-Mustaqbal University College Hilla, Iraq. amir_najah@mustaqbacollege.edu.iq

\section{Different Levels of Engineering Education (EE): Needs and Applications}

\begin{abstract}
Engineering education is often described as being constructivist, suggesting that learning involves constructing an understanding of several components. There is a commonly used series of levels of learning. It is most frequently presented in terms of six levels of understanding. Every learner has to follow these levels. However, the impact of these levels may vary from one learner to another. This paper study the impact of one different level of Engineering Education (EE) on the different background of learners. Furthermore, it investigates the problems that face EE in Iraq and offers several solutions. This work is the first step to a wider investigation of the EE problems and solutions in Iraq.
\end{abstract}

Keywords- Engineering education, research, stimulating education

Received on: $15 / 11 / 2018$

Accepted on: 10/01/2019

Published online: 25/12/2019

How to cite this article: A. Al-juboori, A.A. Al-Akam and A.N. Saud, "Different Levels of Engineering Education (EE): Needs and Applications," Engineering and Technology Journal, Vol. 37, Part C, No. 4, pp. 413417, 20119.

\section{Introduction}

Engineering education is often described as being constructionist (or constructivist), implying that learning involves constructing understanding from several smaller components. This construction can only be performed by the learner, not by the teacher. 'I cannot learn for you, and you cannot learn for me'. The constructivist approach is implicit in Biggs' constructive alignment principle

There is a commonly used series of levels of learning, called Bloom's taxonomy [Bloom, 1956]. It is most frequently presented in terms of six levels of understanding, Table 1, starting with the pure recall of facts from memory and culminating with a sufficiently deep understanding to be able to analyze, synthesize and predict. The levels are often described in terms of the verbs which could be deployed in testing achievement on the Bloom scale. Bloom is, therefore useful when devising teaching approaches but comes into its own when developing assessment tools such as exams and assignments.

Many people have commented that they would like to develop an understanding in their students, not just the ability to memories or parrot information. This is referred to as the difference between deep and surface learning. Marton and Säljö (1976), and subsequently, Entwistle (1988,
2009) have written a lot about these learning styles. However, many researchers have found that any given student can operate in both modes at different times and for different purposes. This is often referred to as strategic learning - doing what is minimally necessary to achieve the desired goal. You could argue that one of the tasks for a teacher is to persuade the student that her desired goal understands, and thus, deep learning would be the best strategy.

\section{EE for any individual}

The phrase 'Engineering Education' phrase no unique meaning because there are many reasons to encourage people to learn about engineering. Firstly, it might be helpful to clarify what engineering education is. It is not about gaining specific practical skills (Although they might be useful or interesting to any individual). Furthermore, it is not about training people to run CFD codes or send CAD designs to a CNC machine or to grow crystals or to sign off structural steelwork. It is about the conceptual, planning and design skills which should precede all these activities. It is about imagining and understanding and predicting, as quantitatively as possible, why and how an engineering objective can be realized and delivered .

Engineering education is usually focused on generic skills and understanding, which can be 
applied in a range of daily tasks that individual without technical back-gourd do, such as frames. The farmer uses the shovel, spade, fork and hoe on a daily bases. The mechanism of this tool is a base on employing some physical rules. The farmer follows these rules subconsciously, without knowing that he applies static forces in a manner that ease the process of digging the gourd for an instant.

Therefore, gaining minimal knowledge about the engineering concept may be useful for many works to understand the world around them. In our example, this knowledge can be reflected in degree titles such as Mechanical Engineering. Many examples can be presented showing the importance of having little information in engineering sectors for every individual. However, this was left to the reader as training to their computer engineering skills in searching and finding the information.

\section{Digging deeply in EE (Lightly)}

After the dissection that has been made by the learner to sink himself in the marvels and the amazing subject of the engineering sciences, he should be trained on several skills. The first step in the $\mathrm{EE}$ is to have the learner has a strong mathematical and scientific background. An interesting sidelight on engineering is provided by the US National Academy of Engineering report written in 2008 entitled changing the Conversation [National Academy of Engineering, 2009]. This contains the comment: “... current messages are framed to emphasize the strong links between engineering and just one of its attributes - the need for mathematics and science skills."

However, the current message often ignores other vital characteristics of EE such as creativity, teamwork, and communication. Many innovative practitioners of engineering education reinforce this view. Pawley [2009] found that academic engineers (i.e. those of us who teach it) see their discipline as being about three things: applied science and mathematics; solving problems, and; making things. One of the questions we should ask ourselves is 'do we expose our students (learns) to enough of the second (communications) and third (teamwork) of these?'

\section{Digging deeply in EE (Strongly)}

Now and after dividing the engineering learners to two levels, individual and students, the engineering students should be learned differently. In addition to the previous skills that have been presented above, there are at least four motives for providing education in engineering:

a) To prepare students for research

Only a minority of engineering graduates will embark on a research career (indeed this is a very small minority in most cases). This educational motive can be considered first because of the prominence (and current dominance) of research in many Departments and Schools of Engineering.

b) To prepare graduates for employment in the engineering industry

This is the 'obvious' intention of both undergraduate and taught postgraduate programs. The implication is that all students aspire to become professionally recognized engineers in one or more engineering disciplines.

c) To prepare engineering/science/numerically literate citizens for society.

Many of the decisions which must be taken in a 21 st-century society involve an assessment of technical issues and/or quantitative data.

d) To provide an intellectually stimulating education.

There was a time when the primary purpose of a university degree program was what we might now call 'general education'. The experience was intended to challenge students to think, rather than to accumulate specific knowledge or skills.

\section{The satisfaction of EE for students}

Although, the previous motivations seem to establish a satisfying EE system, however, the change like university student generations throughout the time may affect the outcome of these motivations. In more details, the Educators cannot, on their own, define and control engineering education because (at least in noncentrally-directed societies) it is necessary for students to sign up before an offered program can be viable. The background, attitudes, and expectations of students are changing increasingly and rapidly. Each generation grows up in a different technological environment, in a different economic climate and according to different social mores. Engineering education cannot stand aside from these factors, even if we believe that many of the fundamental concepts and practices of our chosen profession are relatively timeless.

Furthermore, the prior knowledge and experience of 21 st Century students are long ago in the mists of the 20th century. It was possible to assume that students presenting themselves to university or engineering schools would have constructed models using Meccano. Furthermore, they could, also, have wired a plug for mains electricity (and 
would have received a 110 or $240 \mathrm{~V}$ shock), had changed and mended the tire on their bike, would have taken apart a clock and might even have taken off the cylinder head. Today none of these things is likely, although equivalent students might have keyboard skills and might have added more RAM chips to their laptop. There are two basic reasons for this, first the modern attitudes to safety, and the increased complexity and miniaturization of everyday devices, leading to the black-box syndrome. Many students of engineering learn best by having a concrete experience or making an observation, thinking about it (reflecting and perhaps suggesting a hypothesis or reason), attempting to relate this to an abstract concept and then conducting an experiment (real or imagined) to confirm or refute it. Thus refining their hypothesis and moving on to make a further concrete observation. This is known as the Kolb learning cycle [Kolb, 1984] and is the basis for most developments in the area of experiential learning.

To conclude, the number of factors was described above, and their multiple combinations and interactions, mean that there can be no single 'engineering education' which is fit for every purpose. A well-designed curriculum must surely involve compromises, and at best can only be biased towards a particular graduation outcome, based on some knowledge of the experience and aspirations of the incoming students. Part of the necessary compromise arises from the realization that many students will change their intentions, their attitudes, and their motivation as they progress through their program.

\section{EE Learning outcomes}

Learning outcomes are the statements of the knowledge, understanding, and competencies which our engineering programs are designed to develop in our students. Most universities now demand that every module, program or course has pre-defined learning outcomes, couched in phrases such as 'at the end of this module, the student will be able to ...'. One of the practical challenges for a program director is to ensure that the Los' (Learning Outcomes) delivered by all the modules in the program cover (but do not repeat too many times) the learning outcomes specified for the whole program. This is straightforward in principle during the original design of a program, but difficult to maintain throughout the subsequent inevitable changes in staff, modules, and ideas. It is particularly difficult to maintain in the face of experimental changes in the teaching or assessment practices of individual lecturers, but without experiment, nothing would change at all.

\section{Current status of teaching}

The state of the teaching process nowadays is listed as follows:

a) Contact hours and conventional teaching

Anecdotally the vast majority of engineering and science programs, across the world, are 'delivered' (itself a word which implies teaching rather than learning) using lectures, tutorials, and laboratory classes. A few detailed surveys have been carried out recently. They reveal that, apart from rare periods of intense project activity, students in engineering and science typically have about 20 scheduled 'contact hours' per week time in which they are encouraged (or mandated in some institutions) to be present at a specified time and place to undertake a pre-determined activity. In most programs, these timetabled activities account for the 'delivery' of most of the intended learning outcomes. However, the contact hours are often supplemented by activities such as industrial site visits, research projects and, increasingly, team projects such as design-buildtest exercises.

b) Innovative and less-conventional teaching methodology

Many, indeed probably most - undergraduate programs in engineering and science include a small amount of non-conventional teaching and learning. It is common, in modular programs, to find a small number of modules delivered via problem-based-learning or with varying amounts of active learning. There are also plenty of examples of the use of technology to support student learning, although most of these are at a very elementary level - for example, the use of a VLE (virtual learning environment) to store handouts or Powerpoint presentations for later study.

c) Examples of radical change

Republic Polytechnic in Singapore has adopted an approach which is entirely based on PBL (problem-based learning). Throughout its twoyear Diploma courses in engineering, it presents the students with a new problem every day. Staff undergoes substantial training (starting with a 5day introduction) to help them act appropriately as PBL facilitators as opposed to lecturers - not something which we all pick up naturally. They claim that this approach develops studentcentered learning through 'self-directed discovery and questioning' and that critical reflection takes place throughout the learning process.

They claim that this approach develops studentcentered learning through 'self-directed discovery 
and questioning' and that critical reflection takes place throughout the learning process. These are splendid aims, but there is as yet no evidence that Republic diplomats go on to become better graduate engineers. They certainly should. A bold experiment in PBL was started by the University of Manchester School of Engineering in 2001. The whole of the first two years of the Mechanical and Aerospace Engineering programs were devoted to PBL exercises and too long 'structured learning' sessions which were not lectures but might involve presentations of up to 15 minutes at a time. Early indications were that this approach improved retention and progression rates, motivated most (but not all) students and improved (but not to $100 \%$ ) attendance rates. A major problem with the students was the persistence of a proportion of 'passengers', who contributed little to the learning of their peers. It was found (as with Republic Polytechnic) that staff training was needed to help staff cope with the role of facilitator (rather than a teacher).

Eight years later, in 2009, following a merger of Engineering Schools (UMIST and The University of Manchester) the wholehearted PBL approach has not survived, and their website now states 'Typically, you take lectures and tutorial classes in the mornings with laboratory classes on some afternoons. Active learning is included in some programs through a range of small problem-based projects.' The PBL approach has not been lost but has been seriously diluted. This is in contrast to many medical schools, where PBL was introduced sooner and still thrives.

The evidence for the success or failure of the PBL approach and PBL-trained graduates is sparse. This does not mean that PBL is unsuccessful; It reflects the fact that there is not a single undergraduate Engineering program (in the UK at least) which offers a major PBL experience. Those universities which include PBL (and there are now quite a number of these) do so via a minority of modules and have been able to perform little analysis of their effectiveness.

\section{EE in Iraq (Problems and Solutions)}

Sadly, the application of using the EE to improve the ordinary individual way of thinking in Iraq is quite impossible. This is because of the weakness of the technical background of most of the people. From the student point of view, the engineering colleges in Iraq are still using the traditional ways of teaching engineering. These techniques are extremely out of date and reduce the creativity of the students .

An evaluation for the engineering education in Iraq is extremely required to determine the weakness and find the appropriate teaching technique to improve the learning outcomes. The educations layers presented here can be used to establish a new system to improve the engineering sense of the students, evaluating practical problems, and designs products to fit local needs. However, the author of this paper suggests several solutions could take the EE in Iraq to another level. These are listed below:

A.Applies practical education at a primary and secondary school in more enhanced ways.

B. Add additional training sessions to college students to improve their way of thinking, such as:

a. Lecture in systematical thinking.

b. Applying student technical expertise and use them to improve the experience of the other students.

c. Improve the Visualizing and presenting the engineering data that the student produces.

d. Train the student to solve a number of practical solutions and present and discuss.

e. Several workshops to improve the communications skills of the students.

\section{Conclusion}

The authors identified the problems that face the EE in Iraq based on the previous experience of developed countries. Based on that, the authors have suggested several solutions in this working paper. These suggestions currently in implementation in undergraduate college that is represented by Al-Mustaqbal University College (Biomedical Engineering students). The outcome is in the recording process the response of the student will be archived to be used in future research work and to be kept as a database for more improvement to the program.

\section{References}

[1] ABET, A Guide to the Criteria Harmonization (sic) for Engineering Accreditation, http://www.abet.org/Linked\%20Documents

PDATE/Criteria\%20and\%20PP/EAC\%20

Readers\%20Guide.pdf, 2009.

[2] A. Adams, M. Brewer, I. Marshall, G. Tolley, T. Whelan, "Work-based learning for academic credit in higher education,"

http://www.learningexperience.org.uk/ downloads/work-based-learning-for-ac.pdf, 2004.

[3] N. Alinier and G. Alinier, "Design of an objective assessment tool to evaluate students," basic electrical engineering skills; HEA Engineering Subject Centre Mini-project report, ISBN 879-1-904804-51-2, 2005.

[4] Barkley, Elizabeth, F. "Student Engagement Techniques: A Handbook for College Faculty," Jossey-Bass ISBN978-0-470-28191-8, 2010. 
[5] J. Biggs, "Teaching for Quality Learning at University," Society of Research into Higher Education and OUP, ISBN 0-335-20171-7, 1999.

[6] P.J. Goodhew, "Teaching Engineering," UK Centre for Materials Education, ASIN: B007CHOYHO, 2010. 